\title{
ABRIENDO SENDEROS VIABLES EN UNA HISTORIA TAN MARGINADA COMO GLOBALIZADA. A MANERA DE COMENTARIO
}

\author{
Volker Wünderich
}

Recibido: 28/12/2014 Aceptado: 17/03/2015

\begin{abstract}
Resumen
El comentario refleja los conceptos y consecuencias del "giro global" presentados en el ensayo de V. H. Acuña. Retoma la idea de una "convivencia muy particular de centralidad y marginalidad" en Centroamérica y destaca la necesidad de recuperar la dimensión interactiva en los procesos externos y internos en la región. Además, en los tres artículos siguientes se presentan ejemplos bien logrados de investigaciones en el rol activo (agency) de los centroamericanos frente a las estructuras globalizadas. Se trata del movimiento antiimperialista en El Salvador a principios del siglo XX, la vida pionera de un agrónomo costarricense en servicio de la Revolución Mexicana y el establecimiento de un movimiento civil en defensa de los derechos humanos en la fase decisiva del conflicto en Guatemala. Para recuperar la iniciativa y llegar a una participación activa no basta con defender lo "propio" frente a lo "ajeno". Obviamente hay que desarrollar una conciencia internacionalizada y abrir un camino creativo en el paralelogramo de las fuerzas vigentes.
\end{abstract}

Palabras clave: dossier; centralidad; marginalidad; Centroamérica; cambio creativo.

\begin{abstract}
The text reflects the concepts and consequences of the "global turn" which are presented in V. H. Acuña's essay. It takes up the idea of a "particular coexistence of centrality and marginality" in Central America and sees the necessity of regaining the interactive dimension of external and internal processes in the region. The research which is presented in the following three articles is very interesting evidence of the agency of Central Americans within globally determined structures. It is about the anti-imperialist movement in El Salvador at the beginning of the $20^{\text {th }}$ century, the pioneer life of a Costa Rican agronomist at the service of the Mexican Revolution and the establishment of an independent civil rights movement in the crucial phase of the conflict in Guatemala. In order to regain the initiative and exercise an active participation it is not enough to distinguish yourself from foreign ways and insist on your idiosyncrasy. You have to develop an internationalized conscience and open up a creative path in the parallelogram of forces.
\end{abstract}

Key words: dossier; centrality; marginality; Central America; creative change. 
A primera vista, el tema "Centroamérica en las globalizaciones" no parece ser un tópico novedoso. Es un lugar común en los libros de texto que desde la conquista española esa región ha sido objeto de influencias e intervenciones suprarregionales. Cada colonia sufre, si uno quiere, su caso dramático de "globalización", por ser conquistada y dominada por una potencia superior, con su base de poder en un otro rincón del mundo; pero América Central es un caso especial.

La ponencia programática de Víctor Hugo Acuña ofrece algunos elementos para entender este tema. Por su posición geográfica en el centro del hemisferio occidental, entre dos océanos y dos subcontinentes, América Central siempre ha ofrecido rutas de contacto y tránsito $\mathrm{y}$, por ende, se ha encontrado más expuesta que otras regiones. La globalización ha llegado muy temprano en forma de dominación colonial, de migraciones forzosas, de planes canaleros, de intervenciones militares, de imposición de cultivos exportables, etc. Los próceres de la independencia querían invertir esta condición, pues veían que el istmo estaba dotado por la naturaleza de una posición de centralidad. Una vez eliminado el colonialismo esperaban aprovechar tal condición para construir un país metropolitano y un "emporio" del comercio mundial. Tal visión ha vuelto en reiteradas ocasiones hasta hoy, muchas veces en forma de un unionismo nostálgico.

Sin embargo, las esperanzas basadas en la centralidad geográfica de la región se han perdido en la historia. Por el contrario, el balance histórico muestra que la región hasta hoy ha sido condenada a una situación periférica, y su dependencia de grandes potencias mundiales se ha confirmado a lo largo de los siglos. Por su importancia geoestratégica, el istmo no se ha vuelto más poderoso e independiente, sino más vulnerable. Los pueblos del istmo han tenido que sufrir sus consecuencias como actores subordinados, muchas veces incluso como víctimas.

Retomar el tema de la globalización para Centroamérica en este momento significa superar el nacionalismo metodológico que ha marcado gran parte de los estudios académicos hasta la fecha y reenfocar el contexto global de la historia de la región. Acuña propone abordar los distintos campos de trabajo en el futuro con proposiciones comparativas y relacionales. Así se puede extender el enfoque e integrar perspectivas sobre la creciente transnacionalización, la interconectividad de la región con la política y economía internacionales, su rol en la circulación de las ideas, entre otros aspectos.

En la búsqueda de un compás para una historiografía futura, todavía cabe un tema más: eventualmente faltaría articular la forma específica de la inserción de esta región en el contexto global. Acuña da una pista cuando habla de una "convivencia muy particular de centralidad y marginalidad". Trabajar el tema de la globalización no necesariamente significa concentrarse en los imperios globales. Sería más importante recuperar la dimensión interactiva entre los procesos externos e internos en Centroamérica. Los siguientes artículos presentados en este volumen siguen este camino, adentrándose en las dinámicas que tal cuadro esboza y preguntándose por la participación activa de los centroamericanos en 
las globalizaciones del siglo XX. Buscan averiguar hasta qué punto personas y movimientos sociales podían defender su condición ante el poder de influencias externas, en otras palabras, en qué forma podían hacer vigente su rol activo (agencia) frente a las estructuras dominantes.

El trabajo de Héctor Lindo Fuentes se refiere a las primeras dos décadas del siglo $\mathrm{XX}$, es decir, a una época en la que las pequeñas naciones centroamericanas cayeron víctimas del intervencionismo del gran vecino del Norte. A excepción de algunos casos célebres (como la lucha guerrillera del General Sandino en Nicaragua), los pueblos parecían tener una posición casi indefensa ante la superioridad de las fuerzas. El texto, sin embargo, redescubre el surgimiento de un vivo "movimiento antimperialista" en El Salvador. El autor documenta el protagonismo de los gremios de obreros, artesanos y otras organizaciones populares en el medio urbano. Esas organizaciones se pronunciaron, por ejemplo, en contra de la intervención de los EE. UU. en Nicaragua (de 1912 en adelante), y no se limitaron simplemente a observar en forma pasiva los efectos negativos de la globalización. Así, este trabajo otorga un ejemplo concreto de agencia en una situación de inferioridad, es decir, en una situación más o menos típica en Centroamérica a lo largo del siglo XX.

El activismo de los gremios urbanos se destaca por la frescura y creatividad con que las bases se comprometieron y se declararon responsables de temas de índole suprarregional. Cuando se formaron en el marco del liberalismo establecido, los gremios proclamaron su abstención de los temas políticos (fuera de sus asuntos profesionales y un patriotismo simbólico), pero en su apogeo terminaron en medio de intensos conflictos. Su importancia llegó a un nivel tal, que tanto el Gobierno nacional como la administración en Washington tuvieron que reconocer una oposición fuerte al avance de la influencia imperialista. El texto muestra cómo el presidente Araujo sudaba entre dos fuegos: mientras, que por el lado nacional, proclamaba la defensa de la soberanía, frente a Washington debía servirse del argumento de la gravedad de la protesta nacional para justificar su rechazo de las ingerencias más escandalosas. El texto analiza tal dilema de la manera más objetiva, así que da un buen ejemplo de las contradicciones que la "globalización" puede incubar.

Resaltan, además, dos capacidades del "movimiento antimperialista”. En primer lugar, una sensibilidad sorprendente para identificar el contexto global en ciertos eventos y desarrollos. Aquí no solo se trata de intrusiones obvias como intervenciones militares, sino también de temas más sofisticados como textos diplomáticos (por ejemplo, el tratado Bryan-Chamorro) o las maniobras de Washington para evitar la visita de un intelectual crítico como José Ingenieros a San Salvador. En segundo lugar, la capacidad del movimiento para la comunicación y la formación de redes transnacionalizadas en favor de su agenda política. Las redes muchas veces empiezan en un nivel muy modesto, cuando dos personas de pocos recursos se conocen, comienzan a escribirse cartas, y así se convierten en activistas de la misma causa. Al final, se forma todo un sistema de contactos regionales e internacionales, es decir, una ola de encuentros nacionales, congresos con participación continental, etc. 
Al sacar este movimiento del olvido, el autor logra restituir un componente importante a la dinámica histórica de su país. No solo reconoce un fenómeno descuidado, sino que también rescata a los gremios obreros, artesanos, estudiantiles, etc. del menosprecio que les mostraba el vanguardismo comunista de los años siguientes. Gran parte de la historiografía del movimiento obrero, en boga en los años setenta y ochenta del siglo XX ha seguido esa pista. Para ellos, la negativa de esas organizaciones de aceptar el marxismo y la necesidad de un partido centralizado como orientación general les permitió ser considerados como formas "inferiores" de la lucha. Si bien hace falta reconocer y discutir las limitaciones políticas de tal "movimiento antimperialista", hay que entenderlo como un fenómeno sui generis, sobre todo destacado por su alta conciencia de la globalización de la política nacional y regional de aquellos tiempos.

Marcela Dávalos cuenta la vida de Gonzalo Robles, un costarricense que nació en Cartago en 1892. Para hacer sus estudios académicos tuvo que salir de su país, donde entonces no había universidad. Pero, una vez instalado en los Estados Unidos, como lo deseaba su familia, Robles decidió trasladarse a México, donde se convirtió en agrónomo y vivió la Revolución de 1910. Su compromiso con la reforma agraria y los conflictos dramáticos de los veinticinco años siguientes hicieron de su vida una verdadera película de aventuras globalizadas.

En los años veinte viajó por encargo del Gobierno revolucionario por casi todos los continentes del mundo. El intelectual y agrónomo Robles asumió el rol de mediador transnacional de ideas políticas y científicas. En todos los países donde estudió los sistemas de producción agrícola, registró y asimiló las experiencias locales, siempre con el objetivo de aprovechar tal tesoro para la reconstrucción y modernización del campo en México. Tal vez, la globalización del saber hoy parece una tendencia secular que se desarrolló de forma natural, por sí misma. La biografía transnacionalizada de Gonzalo Robles recuerda que tal tarea requería una verdadera actitud pionera, pues extender el horizonte significaba un proceso largo y laborioso de aprendizaje, e implicaba bastante sacrificio personal en una época cuando la aviación y el auge de la radio todavía estaban en sus primeros inicios. No obstante, Robles dio muestras asombrosas de su movilidad en ferrocarriles y vapores a través del planeta y, en 1923, incluso llegó a la Unión Soviética, entonces la patria de la revolución.

La nota especial de los años veinte fue el optimismo y la fuerte confianza en el progreso. Esos años no solo se destacaban por su enorme afán de aprender y construir escuelas. Robles tenía en mente lo que se podría llamar una globalización positiva. Su generación agrarista fue impregnada por aspiraciones "universalistas". Él y sus amigos fundaron una revista de nombre Germinal, según el ejemplo de Emile Zola. Ahí no solo publicaban estudios técnicos de agricultura, sino también propuestas políticas para el campo y textos de los grandes pensadores, humanistas y socialistas de su tiempo. Así, Robles hizo sus andanzas por los campos del mundo con Zola y Tolstoi bajo el brazo. En la Unión Soviética realizó un verdadero peregrinaje para llegar a la escuela agraria de Yasnaia Poliana, pero la utopía tolstoiana -renovación moral y libertaria por 
el trabajo en el campo- ya no cabía en los planos del partido bolchevique. Sin embargo, Robles, siempre conservó unas ideas básicas de su juventud en Costa Rica; al menos así parece, pues hasta el fin de su vida buscó caminos para la activación de los campesinos productores y siempre proyectaba vías pacíficas a la reforma agraria.

El artículo de Berthold Molden analiza las guerras civiles centroamericanas de los años ochenta en el contexto de la Guerra Fría. Es de común conocimiento que los insurgentes no solo se veían como parte de un movimiento revolucionario de carácter continental, sino incluso "tricontinental". También se reconoce la participación de los gobiernos nacionales en la estratégica de contrainsurgencia norteamericana. En el conflicto chocaban además ideologías políticas de carácter internacional; por un lado, el marxismo revolucionario, combinado con un cristianismo de liberación, con elementos del movimiento indígena y con una fuerte dosis de hispanoamericanismo. Por otro lado, se manifestaba el anticomunismo (Molden insiste en que eso también fue una ideología de carácter internacional) con su fuerte presencia en las fuerzas armadas, los medios de comunicación, etc. Según esta versión “dualista” de la globalización, Centroamérica parecía condenada a ser simplemente el campo de batalla de una lucha global. El autor advierte, sin embargo, que en el caso de Guatemala tal versión simplista correspondía al interés de los militares de externalizar las causas del conflicto interno. Denunciaban a sus adversarios de ser comprados por el "comunismo internacional", y al mismo tiempo querían trasladar la responsabilidad de sus propios crímenes hacia los actores extranjeros.

Para evitar tales oposiciones simplistas de carácter "propio-ajeno", "interno-externo" u "original-copia" y tener en cuenta los entrecruzamientos sofisticados entre lo nacional y lo internacional, Molden sigue un enfoque metodológico llamado Historia Cruzada (historie croisée), el cual se concentra menos en la movilidad geográfica de las ideas, estrategias, recursos etc., sino que busca más bien los impactos que un contacto entre actores o entornos históricos puede dejar en todos los participantes.

El ejemplo en este estudio es el surgimiento de un movimiento civil de oposición en el conflicto guatemalteco. Es el movimiento de derechos humanos el que tiene sus principios en la aparición del Grupo de Apoyo Mutuo (GAM) en 1984, y asume una decisiva importancia en el proceso de paz y la eventual caída de la dictadura militar en los años noventa. Aquí participan entonces nuevas organizaciones como la Asociación de la Sociedad Civil (ASC), las comisiones de verdad (REMHI y CEH) y otras. El movimiento se establece como una tercera fuerza en el conflicto, con lo cual se niega efectivamente el carácter "dualista" de este. El Gobierno mantiene que ese movimiento no es más que un nuevo disfraz de la guerrilla, pero el movimiento muestra su independencia y su propia lógica política, al otorgar muestras impresionantes de su agencia. Además, insiste en sacar sus propias conclusiones de la violencia en el país, mediante la investigación de los crímenes, la búsqueda de los desaparecidos, el establecimiento de una comisión de la verdad, la reconciliación solo en base de la "verdad", etc. Mientras impone una nueva agenda en el contexto nacional, este movimiento actúa en plena conciencia sobre la importancia de la "comunidad internacional" y entrega pruebas concretas de que las organizaciones de derechos humanos son altamente internacionalizadas. El movimiento 
en Guatemala se refiere a los procesos de pacificación en otros países como Argentina, Chile, África del Sur, etc. Al mismo tiempo, el movimiento apela a la opinión pública mundial y se dirige a las Naciones Unidas como el guardián tradicional de los derechos humanos, incluso logra que una misión especial de la ONU (MINUGUA) asuma la mediación del proceso de paz, para así romper el cerco que los militares habían puesto tanto a la oposición civil como a los insurgentes.

En otras palabras, el movimiento es un ejemplo contundente de una nueva forma de globalización en Centroamérica. El proceso de paz a partir de 1987 ya había significado un camino para autoempoderar a los gobiernos de la región. Eso pasó en la medida en que los presidentes (con el costarricense Óscar Arias a la cabeza) lograron superar la lógica de la Guerra Fría y, por ende, salir de su subordinación correspondiente a la política de la Casa Blanca. Guatemala, sin embargo, tuvo el conflicto más brutal y embrollado. Una salida solo fue posible gracias a la aparición de un nuevo fenómeno, un movimiento civil que se mostró capaz de cambiar la correlación de fuerzas mediante su énfasis en un nuevo campo globalizado de acción: los derechos humanos.

El uso del "giro global" para la historiografía de los países de América Central no puede concentrar todos los esfuerzos en el desarrollo de la nueva disciplina "Historia Global". Tampoco se trata de insistir en la determinación del destino de las naciones de la región desde fuera como un hecho consumado. Al contrario, los tres artículos de este dossier edición dan un ejemplo de lo que agencia puede significar para salvadoreños, costarricenses o guatemaltecos en las condiciones de la globalización del siglo XX. Más bien se trata de salir del "nacionalismo metodológico" predominante y poner cada objeto en estudio, sea de carácter local, regional o nacional, en su debido contexto transnacional. Precisa una reorientación del trabajo del historiador.

Así, en su artículo programático, Víctor Hugo Acuña llama a hacer una historia empírica de conexiones y entrecruces, además de lanzarse al campo descuidado de la historia comparada. La realidad globalizada se construye por una articulación delicada de factores internos y externos. La mera reconfirmación de los elementos "propios" e identitarios falla ante tal reto exigente. Solo estudios empíricos e históricos podrán entrar a la dinámica específica detrás de un imaginario reducido, sea de imperios todopoderosos, de historias patrias o de tradiciones locales.

Volker Wünderich. Alemán, Dr.phil, Privatdozent y apl.Prof. en el Historisches Seminar de la Leibniz-Universität Hannover. Investigaciones y docenturas en América Central. Colaborador permanente de la Akademie für Internationale Zusammenarbeit (GIZ), Bad Honnef. Campos de trabajo: historia latinoamericana, alemana y transatlántica; cuestión étnica e historia del café: producción y consumo. Algunas publicaciones: Sandino. Una biografía política, 2010; Zentralamerika heute (ed.con Kurtenbach y otros), Frankfurt 2008; Kaffeewelten (ed. con Christiane Berth y Dorothee Wierling), Göttingen, 2015.

Contacto: wuenderich@hist.uni-hannover.de 